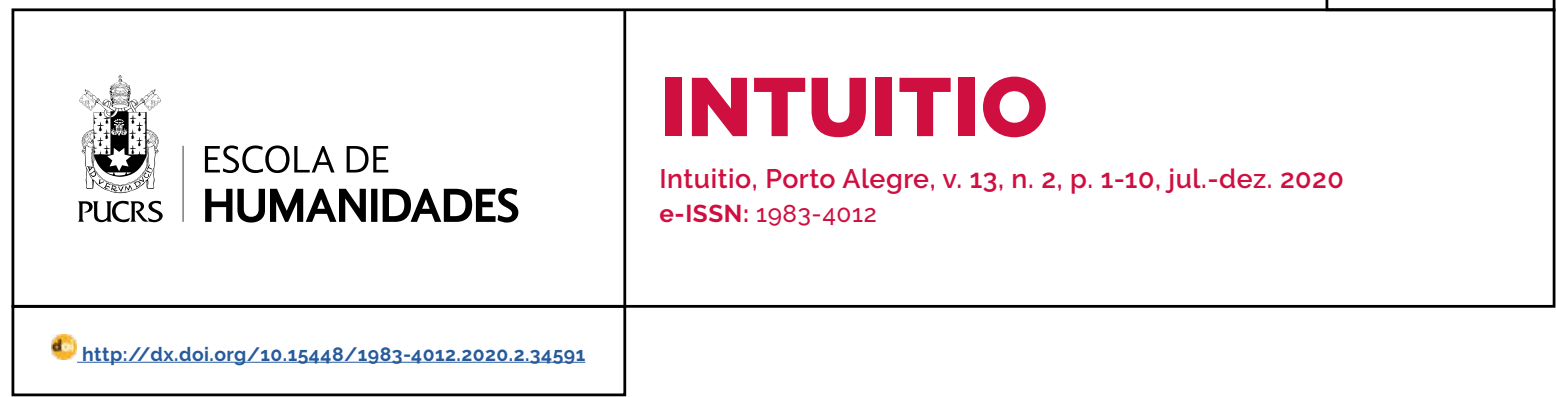

SEÇÃO: ARTIGO

\title{
A crítica ao utilitarismo em O Liberalismo Político (1993) de John Rawls
}

\author{
The criticism to utilitarianism in Political Liberalism (1993) by John Rawls
}

\section{Eloi Fabian ${ }^{1}$}

orcid.org/0000-0001-7893-1882

eloi.fabian@uffs.edu.br

Recebido em: 25/6/2019

Aprovado em: 8/6/2020

Publicado em: 19/2/2021
Resumo: A postura de Rawls na obra de 1993 - não obstante a rápida referência que apresenta às teorias sistemáticas do Utilitarismo de Bentham, Sidgwick, Edgeworth, enquanto teorias razoáveis e abrangentes - é em relação a Mill e seu conceito de individualidade que ele dedica a maior parte da critica ao Utilitarismo. Uma critica caracterizada por demostrar as dificuldades de uma doutrina abrangente, fundada numa perspectiva moral, não politicamente legitimada e que não confere um caráter público para as bases da justiça. O Utilitarismo desconsidera a pluralidade de costumes, crenças, concepções de mundo, das sociedades contemporâneas e não percebe a relevância e a necessidade de principios de justiça formulados publicamente pelos cidadãos livres e iguais envolvidos, através de um neocontratualismo operado pelo véu da ignorância (veil of ingnorance) na posição original. A crítica ao utilitarismo, portanto, gravita mais em torno deste aspecto mais específico e restrito em O Liberalismo Político se comparado com a obra de 1971. A teoria da justiça como equidade por meio do equilíbrio reflexivo, o consenso sobreposto e a nova perspectiva de democracia constitucional são amplamente apresentadas como uma alternativa viável e adequadamente fundamentada frente ao Utilitarismo. É o que se pretende explicitar neste artigo.

Palavras-chave: Liberalismo Político. Utilitarismo. Mill. Individualidade. Consenso Sobreposto.

Abstract: Rawls's stance in the 1993 book - despite his quick reference to the systematic theories of Bentham's utilitarianism, Sidgwick, Edgeworth, as reasonable and comprehensive theories - is in relation to Mill and his concept of individuality which he devotes most from criticism to utilitarianism. A critique characterized by demonstrating the difficulties of a comprehensive doctrine, founded on a moral perspective, not politically legitimized and that does not confer a public character to the bases of justice. Utilitarianism disregards the plurality of customs, beliefs, worldviews, contemporary societies, and does not realize the relevance and necessity of principles of justice formulated publicly by the free and equal citizens involved, through a neocontractualism operated by the veil of ignorance in the original position. The critique of utilitarianism therefore gravitates more closely to this more specific and restricted aspect in Political Liberalism compared to the work of 1971. The theory of justice as fairness through reflective equilibrium, overlapping consensus, and the new perspective of democracy is widely presented as a viable and adequately grounded alternative to Utilitarianism. This is what we want to explain in this article.

Keywords: Political Liberalism. Utilitarianism. Mill. Individuality. Overlapping Consensus 


\section{As premissas do 0 Liberalismo Político e as respostas aos críticos de Uma Teoria da Justiça ${ }^{2}$}

O Liberalismo Político (Political Liberalism) (1993), considerada a segunda maior obra de John Rawls, é composta por oito conferências alocadas em três partes: 1) O Liberalismo Político: elementos básicos (conferências I, II e III); 2) O Liberalismo Político: três ideias centrais (conferências IV, V e VI); e 3) A Estrutura Institucional (conferências VII e VIII).

Já na primeira conferência Rawls enfatiza sua já manifesta preocupação em desenvolver e aperfeiçoar a teoria da justiça como equidade para os desafios contemporâneos diante do pluralismo de doutrinas e crenças razoáveis, assim como, pela necessidade da cooperação social entre cidadãos livre e iguais, pertencentes a uma democracia constitucional. Uma teoria que considere a tolerância, a justiça e a estabilidade como sua tarefa principal. O Liberalismo Político, portanto, visa responder sobre "qual a concepção de justiça mais apta a especificar os termos equitativos de cooperação social entre cidadãos considerados livre e iguais, e membros plenamente cooperativos da sociedade durante a vida toda, de uma geração até a seguinte" (RAWLS, 2000, p. 45).

Outro grande desafio da obra é responder a um conjunto de críticas resultantes da publicação de sua teoria em Uma Teoria da Justiça (Theory of Justice) (1971), especialmente em relação a temas como a concepção de Pessoa numa perspectiva mais política que moral, resultado de um modelo metodológico construtivista e coerentista. Uma teoria política neocontratualista com fundamento prático (ação/razoável) e não teórico (verdade/racional). E de outra parte, também as objeções dos chamados teóricos "comunitaristas", as quais foram muito bem sintetizadas por Gondim e Rodrigues:

1) uma concepção abstrata de pessoa que é consequência da posição original sob o véu da ignorância; 2) principios universais (deontológicos) com a pretensão de aplicação em todas as sociedades, criando uma supremacia dos direitos individuais em relação aos direitos cole- tivos; 3) não possui uma teoria da sociedade em função de seu contratualismo, trazendo como consequência uma atomização do social, em que a pessoa é considerada enquanto átomo isolado; 4) utiliza a ideia de um Estado neutro em relação aos valores morais, garantindo apenas a autonomia privada (liberdade dos modernos) e não a autonomia pública (liberdade dos antigos), estando circunscrita a um subjetivismo ético liberal; 5) é uma teoria deontológica e procedimental, estabelecendo uma prioridade absoluta do justo em relação ao bem (GODIM; RODRIGUES, 2011, p. 26)

Todos esses pontos abrem um flanco muito interessante e amplo de discussões por apresentar uma relevância e várias implicações, e que já resultaram em muitos estudos e publicações. Nosso objetivo neste trabalho, no entanto, é priorizar a análise sobre o debate crítico em relação à tradição Utilitarista em LP3 ${ }^{3}$ especialmente no que diz respeito sua relação com as chamadas doutrinas abrangentes (comprehensive doctrines). É o que tentaremos desenvolver nos próximos pontos deste ensaio, dando sequência ao estudo já iniciado acerca desta crítica na obra Uma Teoria da Justiça.

\section{Localizando a crítica ao Utilitarismo em $O$ Liberalismo Político}

A crítica ao Utilitarismo em Uma Teoria da Justiça resulta de uma tentativa de apresentar a teoria da justiça como equidade enquanto uma alternativa ao Intuicionismo, Perfeccionismo e ao Utilitarismo. Neste contexto, Rawls tematiza e critica o chamado Utilitarismo Clássico (Bentham, Mill, Sidgwick, Edgeworth) e Utilitarismo Médio (Wicksell, Smart, Brandt, Harsanyi). Ela pode ser resumida em quatro pontos: i) o modo de argumentar do Utilitarismo não leva em conta a distinção entre as pessoas; ii) o Utilitarismo pode permitir que nem todos os cidadãos respeitem os Princípios de Justiça; iii) O Utilitarismo falha no sentido de garantir as liberdades e o justo, ao passo que Rawls procura sempre privilegiar o justo (right) sobre o Bem (good); iv) Os fundamentos que garantem a estabilidade da estrutura básica requerem principios de justiça justificados 
e reconhecidos publicamente. Estas críticas estão mais presentes em $\mathrm{TJ}$, as quais procuramos tematizar em um outro ensaio.

No contexto da obra O Liberalismo Politico a crítica ao Utilitarismo leva em conta o ponto 4 acima referido, mas é apresentada numa outra perspectiva e redimensionada. Ela está conectada com a pretensão central da obra de defender um liberalismo político enquanto teoria fundamental para o contexto político-filosófico contemporâneo.

Nela, o filósofo americano pretende defender com maior ênfase, clareza e profundidade uma teoria da justiça como equidade na perspectiva de um liberalismo político que preconize uma concepção política de justiça, cujo alcance e interferência na vida dos cidadãos seja menor. E sempre no sentido de garantir a tolerância, o respeito em relação às liberdades de pensamento, crença, opinião e a igualdade para os membros cooperativos da sociedade, durante a vida toda e para as próximas gerações. Isso implica em estabelecer uma crítica às chamadas doutrinas filosóficas, morais ou religiosas abrangentes (comprehensive doctrines). Dentre as doutrinas filosóficas abrangentes, Rawls trata principalmente do Utilitarismo de Mill4 ${ }^{4}$, expresso através da noção de individualidade, bem como, do conceito de Autonomia de Kant. Teorias que, de acordo com seu ponto de vista, pretendiam ter um alcance muito maior.

Neste sentido, o conceito de consenso sobreposto (overlapping consensus) é fundamental para implementar a possibilidade de contemplar as diferentes doutrinas filosóficas, morais e religiosas abrangentes, consideradas razoáveis dentro de um Estado constituído através de um contrato e configurado numa democracia constitucional. $O$ consenso sobreposto, porém, não pode integrar aquelas doutrinas abrangentes que representam uma ameaça ou a inviabilidade para produzir um espaço de sociabilidade na medida em que podem ser consideradas irracionais, não razoáveis. Ao mesmo tempo, revela-se também de uma importância fundamental nesse debate, a diferença entre o Racional e o Razoável, a noção de pessoa numa perspectiva mais política que moral, a prioridade do justo (right) sobre o bem (good). É nesse contexto e lugar que a crítica ao Utilitarismo é desenvolvida em LP e que passaremos a dar enfoque.

\section{Os Pontos da crítica}

Diferentemente da obra de 1971, em O Liberalismo Político (1993), a crítica ao Utilitarismo não é feita em seções especificas e localizadas. As referências, principalmente ao Utilitarismo de Mill e seu conceito de individualidade, são trazidas no debate de modo esparso ao longo das oito conferências, sempre no sentido de enfatizar sua diferença em relação as doutrinas filosóficas abrangentes.

De acordo com Samuel Schefler,

\begin{abstract}
no Liberalismo Político, o contexto de discussão foi deslocado. O objetivo agora é mostrar como as instituições liberais podem conquistar estabilidade em condições de pluralismo para configurar-se sobre diversas fontes de sustentação moral. Neste contexto, o utilitarismo, através de seu lugar proeminente na tradição do pensamento liberal e suas mais especificas afinidades com a visão do próprio Rawls, apresenta-se com um aliado natural (SCHEFLER, 2006, p. 453). ${ }^{5}$
\end{abstract}

O objetivo central desse debate é caracterizar a teoria da justiça como equidade, gestada no interior de uma perspectiva neocontratualista, através de um método coerentista e procedimental, diferenciando-a das doutrinas razoáveis abrangentes. Uma teoria da justiça como equidade na qual predomina uma noção mais política que moral de pessoa, com ênfase na primazia do justo (right) sobre o bem (good).

Jonathan Riley reforça essa constatação de que

\footnotetext{
4 Há vários trabalhos investigativos que demonstram certas aproximações das teorias de Rawls com o liberalismo de Mill, incluindo análises das obras O Liberalismo Político (1993) e Conferências sobre história da filosofia política (2007). Sobretudo nestas duas obras, nas quais o autor se distancia do Liberalismo Iluminista (Enlightmenment liberalism) de Kant. Ver: REYNOLDS, Alan. Reconsidering the Connection between John Stuart Mill and John Rawls. Minerva - An Internet Journal of Philosophy 17. 2013, p. 1-30. Também: RILEY, Jonathan. Rawls, Mill and Utilitarianism. In.: A Companion To Rawls. Edited by Jon Mandle, David A Reidy. Library of Congress Cataloging. 2014, p. 397-412.

5 "In Political Liberalism, the context of discussion has shifted. The aim now is to show how liberal institutions can achieve stability in conditions of pluralism by drawing on diverse sources of moral support. In this context, utilitarianism, with its prominent place in the traditions of liberal thought and its various more specific affinities with Rawls's own view, presents itself as a natural ally".
} 
o foco de discussão em relação ao Utilitarismo em O Liberalismo Politico está, basicamente, voltado para a teoria de Mill, especialmente por ser caracterizada como uma doutrina abrangente (comprehensive doctrine).

(...) originalmente na terceira parte de Uma Teoria da Justiça, porém, mais tarde abandonada (como um argumento de estabilidade geral) em O Liberalismo Politico, uma vez que ele admite que a teoria de Mill é uma doutrina abrangente do bem, isto é, daquilo que é racional nos desejos humanos, é igual a Kant na medida em que ambas dão importância suprema para a autonomia moral (RILEY, 2014, p. 405). ${ }^{6}$

\subsection{Uma concepção politica de pessoa e de} justiça

Já na primeira conferência (/deias Fundamentais) Rawls procura deixar claro algumas dessas distinções no que diz respeito a diferença entre uma concepção política de pessoa e de justiça frente as concepções morais e abrangentes:

Nesse sentido, uma concepção política de justiça difere de muitas doutrinas morais, pois estas são comumente consideradas visões gerais e abrangentes. O utilitarismo é um exemplo conhecido. O principio de utilidade - independentemente de como seja entendido - tem sua aplicação, de modo geral, estendida a todos os tipos de objeto, da conduta dos individuos e das relações pessoais à organização da sociedade como um todo, bem como ao direito das gentes (RAWLS, 2000, p. 55).

Há um perceptível esforço em LP de demonstrar que a teoria da justiça como equidade está fundamentada na perspectiva de uma teoria política7, não metafísica. ${ }^{8}$ Isso significa que ele não propõe um fundacionismo inquestionável.

Rawls procura reverter uma perspectiva tradi- cional da teoria política onde o racional (Imperativo Categórico, o em si, verdadeiro, o teórico) pretendia configurar-se como um sólido fundamento, passando a priorizar o razoável (Imperativo Hipotético, fins, o prático). Neste ponto, filia-se inicialmente em Uma Teoria da Justiça, com as devidas distinções da tradição kantiana, porém, passa a estabelecer uma complementaridade entre o construtivismo moral e político ${ }^{9}$, caminhando cada vez mais para a alternativa politica em O Liberalismo Politico.

Rawls pretende conectar essa noção mais politica da sua teoria, justamente para evitar modelos que impedem que um liberalismo político seja, de fato, viável. Seu conceito de pessoa também passa a ser mais político e está baseado em ideias básicas, intuitivas, presentes na cultura pública de uma democracia.

A concepção política de pessoa (cidadãos) $)^{10}$ foi pensada em sentido normativo para o modelo de representação na posição original (original position). Rawls não está tratando aqui de uma teoria da natureza humana. Uma abordagem antropológica implicaria vários outros elementos que fogem de seu propósito principal, tais como as estruturas e um conceito sistemático de homem.

Ele esclarece e avalia o contraste entre filosofia política e filosofia moral ao ressaltar que

O objetivo da filosofia política - sempre vista como parte da filosofia moral, ao lado da teologia e da metafísica - é, portanto, determinar a natureza e o conteúdo dessa concepção do bem. O utilitarismo clássico de Bentham, Edgeworth e Sidgwick faz parte dessa tradição dominante (RAWLS, 2000, p. 180).

No entanto, ele sabe das implicações e das dificuldades dessa noção exclusivamente moral.

A teoria da justiça como equidade, apesar de

\footnotetext{
6 “(...) originally made in the third part of A Theory do Justice but later abandoned (as a general stabilty argument) in Political Liberalism, because he assumes that Mill's comprehensive doctrine of the good, that is, of what it is rational for humans to desire, is like Kant's insofar as both give supreme importance to moral autonomy".

7 Uma concepção política de justiça é caracterizada por: a) ser elaborada para um determinado fim, a estrutura básica da sociedade; b) não pode ser derivada da concepção abrangente de bem; c) uma concepção que deve ser fundada em certas intuições fundamentais latentes próprias de uma cultura democrática.

8 Neste particular, ver interessante ensaio: DALSOTTO, Lucas Mateus. Os limites da teoria de John Rawls: uma teoria política e não metafísica. In:: CARVALHO, M; NASCIMENTO, M. M; WEBER, T. Justiça e Direito. Coleção XVI Encontro. ANPOF: ANPOF, 2015, p. 132-140.

9 Sobre este aspecto ver: DALSOTTO, Lucas Mateus. Justificação moral e acordo politico: sobre a possibilidade de uma complementariedade entre um construtivismo moral e um construtivismo político na teoria de Rawls. Edição Especial n. 42. Barbarói: Santa Cruz do Sul, jul./dez. 2004, p. 75-87.

10 Cidadãos que se consideram livres em três sentidos: i) pelo fato de conceberem a si mesmos e aos demais como moralmente capazes de possuir a faculdade moral de ter uma concepção de bem; ii) consideram-se livres na medida em que são fontes autoautenticadas de reinvindicações legítimas; iii) entendem-se como livres porque são capazes de assumir responsabilidade sobre seus próprios fins (DALSOTTO, 2014, p. 132).
} 
ser uma teoria política, também pode ser caracterizada por fazer uso de uma concepção moral, muito mais na obra Uma Teoria da Justiça que em o Liberalismo Político. Entretanto, não se trata de uma teoria abrangente como as teorias de Kant e Mill. Seus aspectos morais são equacionados através do equilibrio reflexivo (reflective equilibrium), cujo papel é instaurar a coerência entre os juizos morais particulares dos agentes e os princípios éticos estabelecidos, no caso, os princípios de justiça. Estes princípios orientarão, de modo procedimental, as regras para o agir moral, instaurando uma complementariedade entre a cultura política democrática de uma sociedade.11

Kant e Mill são apontados como teóricos fundamentais por sua contribuição ao pensamento liberal, no entanto, ambos apresentaram ideais morais como o fundamento válido de um regime democrático. É exatamente isso que neocontratualismo de Rawls, na perspectiva de um liberalismo político, pretende evitar na medida em que procura contemplar um conjunto mais amplo de doutrinas abrangentes razoáveis que são passiveis de um consenso sobreposto.

Conforme Rawls, essa autonomia plena da vida política deve ser distinguida dos valores éticos da autonomia e da individualidade que pretende ser aplicados à vida como um todo, tanto social quanto individual, no modo como foram apresentados pelos liberalismos abrangentes de Kant e Mill. A justiça como equidade enfatiza esse contraste e reafirma a autonomia política, mas deixa o peso da autonomia ética para ser decidido pelos cidadãos separadamente, à luz de suas doutrinas abrangentes.

Justamente, neste ponto de vista político que a teoria da justiça como equidade de Rawls se distingue totalmente da teoria moral utilitarista, por exemplo. Esta procura aplicar o princípio da utilidade, em qualquer uma de suas formulações, para todos os tipos de objetos e ações da estrutura básica da sociedade. O princípio de utilidade pretende, indistintamente, ser aplicado a todas as formas sociais, sejam públicas ou institucionais, quanto privadas e pessoais. Trata-se, portanto, de uma teoria ampla que rejeita a ideia de que existem principios fundamentais de justiça que podem ser politicamente reconhecidos e que não compartilham de nenhuma concepção moral específica.

Rawls pretende deixar claro que nenhuma concepção moral geral consegue ter a habilidade de propor um fundamento publicamente reconhecido e aceito pelos cidadãos, no sentido de estabelecer os princípios de justiça numa democracia constitucional. Isso porque, se observarmos a história do pensamento democrático, sempre existiu muitas discordâncias a respeito de qual seria a forma mais razoável e adequada de organizar e pôr em prática os valores da liberdade e igualdade por parte das instituições, as quais Rawls denomina de estrutura básica (basic structure) da sociedade. Nesta direção, "a teoria de Rawls consegue minimizar e limitar a extensão dessa discordância pública sobre as controvérsias politicas mais importantes, dado a impossibilidade de alcançar uma discordância completa e estável acerca das mesmas" (DALSOTTO, 2015, p. 134).

A justiça como equidade procura partir de algumas convicções fortes e amplamente consensuadas pelos indivíduos pertencentes a um Estado. Nos nossos dias, por exemplo, mesmo que ainda existam casos de escravidão, é possivel afirmar com segurança que nenhuma pessoa razoável defende essa prática. Esses consensos mínimos sobre a sociabilidade é que servem de pontos de partida para repensar as noções de justiça que levam em conta a razoabilidade e a estabilidade de uma sociedade democrática, marcada pela existência de concepções de bem (good) variadas, muitas vezes conflitantes. Esse é o motivo pelo qual o construtivismo coerentista de Rawls pretende corrigir e ser mais efetivo que a teoria utilitarista, por exemplo.

O autor de LP reforça essa distinção do seguinte modo:

Essa conclusão não significa que os liberalismos de Kant e Mill não sejam doutrinas razoáveis e apropriadas que levam uma pessoa a

\footnotetext{
${ }_{11}$ Acerca deste tópico ver: SILVEIRA, Denis Coitinho. Posição Original e Equilibrio Reflexivo em John Rawls: o problema da justificação. Trans/Form/Ação, São Paulo, 32(1): 139-157, 2009.
} 
apoiar instituições democráticas. Mas são duas doutrinas desse tipo entre outras e, por conseguinte, apenas duas das visões filosóficas com probabilidade de persistir e conquistar adeptos num regime democrático razoavelmente justo (RAWLS, 2000, p. 181 - nota 3).

Na mesma direção, Rawls alerta que a mesma situação se aplica a todas doutrinas filosóficas e morais abrangentes e razoáveis, sejam elas religiosas ou não. Uma sociedade unida por uma forma razoável de utilitarismo ou pelo liberalismo razoável de Kant ou Mill, necessitaria igualmente das sanções do poder estatal para se manter. Ele chama isso de "fato da opressão" (RAWLS, 2000, p. 81).

Pode se dizer que o fundamento da teoria da justiça como equidade não é nem metafísico e nem epistemológico, mas prático. Se de um lado ela não consegue eliminar os conflitos existentes entre as diferentes concepções de bem existentes, por outro procura permitir que se viabilize um modo possivel para obter a unidade de uma sociedade e sua estabilidade. Portanto, essa teoria política parte de dois pressupostos básicos: 1) a sociedade compreendida como um sistema equitativo de cooperação ${ }^{12}$; 2) uma concepção política de pessoa. Rawls chama isso de vida política compartilhada.

Essa ideia de uma vida política compartilhada não envolve a ideia de autonomia de Kant nem a ideia de individualidade de Mill, no sentido de valores morais que fazem parte de uma doutrina abrangente. $\mathrm{O}$ apelo diz respeito mais ao valor político de uma vida pública conduzida de acordo com termos que todos os cidadãos razoáveis possam aceitar como equitativos (RAWLS, 2000, p. 143).

É esta perspectiva política que viabiliza o consenso sobreposto.

\subsection{O Utilitarismo como doutrina abrangente razoável}

Um liberalismo político na perspectiva da teoria da justiça como equidade procura apresentar um modo de garantir estabilidade (stability) de uma sociedade bem ordenada, diante do fato do pluralismo razoável (fact of reasonable pluralism). Rawls entende que nenhuma doutrina abrangente razoável pode garantir essa estabilidade, dai a necessidade de um consenso sobreposto (overlapping consen$s u s)^{13}$ de todas elas dentro de um mesmo Estado.

Rawls procura fazer muitas ressalvas no decorrer de O Liberalismo Político que, mesmo sendo a teoria da justiça como equidade considerada política, ela também faz uso de uma concepção moral. Entretanto, essa concepção moral não é abrangente como nas teorias Utilitaristas, a exemplo das teorias de Mill (individualidade) e a Kant (autonomia). Embora tenham oferecido grandes contribuições ao pensamento liberal, estes dois últimos autores apresentam suas doutrinas como o único fundamento válido de um regime democrático. Assim, nenhuma doutrina abrangente (comprehensive doctrines) é apropriada enquanto concepção politica para um regime constitucional.

Os liberalismos de Kant e Mill podem levar a exigências destinadas a promover os valores da autonomia e da individualidade, como ideias que devem governar grande parte da vida, quando não sua totalidade. Mas o liberalismo político tem um objetivo diferente e requer muito menos (RAWLS, 2000, p. 247).

Apesar de uma certa semelhança entre os valores do liberalismo político de Rawls com os valores dos liberalismos abrangentes de Kant e Mill, é importante perceber as suas amplas distinções. Isto, tanto de alcance, no grau de generalidade entre um liberalismo político e um liberalismo abrangente.

Segundo Forst (2010, p. 213), que faz uma leitura político-pragmática do liberalismo político de Rawls, a intenção do filósofo americano é resolver o problema da estabilidade. Para isso, avança com preocupação na direção de acordar um consenso

\footnotetext{
12 A noção de cooperação social está alicerçada em três ideias: i) a cooperação social é regida por regras que são publicamente reconhecidas e por procedimentos que são seguidos por aqueles que cooperam; ii) a cooperação social implica que os principios contrafactualmente acordados sejam equitativos e aceitos por todos, assim como os termos da cooperação sugerem uma ideia de reciprocidade e intergeracionalidade; iii) e por fim, a cooperação social exige que se tenha a ideia de vantagem racional de cada participante em atingir a consecução de seu bem especifico. RAWLS, J. Justiça e democracia. São Paulo: Martins Fontes, 2000, p. 215

13 De acordo com Silveira "a categoria de consenso sobreposto é introduzida para estabelecer uma ideia de uma sociedade bem-ordenada mais realista e ajustada às condições históricas e sociais das sociedades democráticas, o que inclui o fato do pluralismo razoável (reasonable pluralism)" (SILVEIRA, 2007, p. 14).
} 
mínimo para a manutenção da paz social. Entretanto, Rawls procura distinguir sua teoria em dois momentos: 1) o da justificação moral independente e autossustentada; 2) e o estágio da possibilidade da estabilidade social, a partir de um consenso sobreposto. Percebe-se, assim, uma engenharia bastante distinta daquela empreendida pelas teorias abrangentes como o Utilitarismo.

Rawls descreve o Utilitarismo como uma teoria geral abrangente, aspecto que procura evitar:

O contraste com o utilitarismo clássico: este costuma ser interpretado como uma teoria geral por completo. Claro que isso é verdade no que diz respeito à doutrina clássica, tal como definitivamente formulada por Sidgwick. O principio da utilidade aplica-se igualmente a todas as formas sociais e às ações dos individuos (RAWLS, 2000, p. 311-2).

Em nova ideia de liberalismo político é viabilizada metodologicamente através do consenso sobreposto que procura chegar até as ideias fundamentais. Aquele lugar em que a justiça como equidade é desenvolvida e procura ter uma atuação determinada no momento em que este consenso consegue envolver e abarcar os principios e valores de uma concepção política, tendo como base de apoio a estrutura básica da sociedade para estabelecer uma base pública de justificação (public basis of justification). Será essa base que promoverá a unidade e a estabilidade social marcada pelo pluralismo razoável.

\section{Para além do Utilitarismo}

Como vimos, na obra O Liberalismo Político o Utilitarismo é caracterizado por Rawls como uma "teoria genérica" que rejeita a ideia de que os primeiros princípios especiais são necessários. O utilitarismo defende que todos os critérios e elementos para a estrutura básica da sociedade já estão postos dentro da própria teoria. Esse é um problema deveras complicado para os desafios de democracias constitucionais, Estados democráticos e plurais contemporâneos.
Para o autor,

\begin{abstract}
A liberdade e a igualdade de pessoas morais requerem uma forma pública, e o conteúdo dos dois principios satisfaz essa exigência. Isso contrasta, por exemplo, com o utilitarismo clássico, que considera básica a capacidade de sentir prazer e dor, ou a capacidade para certas experiências intrinsecamente valiosas, definidas de tal forma que nenhuma expressão institucional especifica se faz necessária, embora certas formas sociais sejam, evidentemente, superiores a outras, como meios mais efetivos de se alcançar um ganho líquido maior de felicidade, ou uma soma maior de valor. (RAWLS, 2000, p. 334).
\end{abstract}

Já para Rawls, uma das principais contribuições e objetivos da teoria da justiça como equidade é mostrar que os dois principios de justiça propiciam uma compreensão melhor das exigências de liberdade e da igualdade numa sociedade democrática, em relação aos principios primeiros associados às doutrinas tradicionais do utilitarismo, do perfeccionismo ou do intuicionismo. São esses aspectos, juntamente com os dois princípios de justiça formulados na posição original (original position), que se constituem numa alternativa a estes desafios.

Uma conclusão óbvia depreendida da crítica de Rawls ao Utilitarismo em O Liberalismo Politico: o seu liberalismo político exige menos em relação aquelas doutrinas destinadas a promover valores como Autonomia (Kant) e Individualidade (Mill). Isso porque, o primeiro é um tipo de liberalismo político, ao passo que o segundo um liberalismo moral e abrangente (Kant e Mill). A liberdade e igualdade das pessoas morais requer uma forma pública e conteúdo de princípios, diferentemente do Utilitarismo que considera como critério uma certa noção de dor/prazer.

Os dois princípios ${ }^{14}$ de justiça, reafirma Rawls, cumprem melhor as exigências de liberdade e igualdade que a perspectiva do Utilitarismo, Perfeccionismo e Intuicionismo. Neste ponto, o consenso sobreposto endossa a concepção política com base numa doutrina filosófica abrangente liberal como a de Kant e Mill. 
A aceitação da concepção política deriva da doutrina abrangente e depende unicamente dela pelo fato de uma concepção política poder relacionar-se com uma doutrina abrangente como o Utilitarismo que admite limites, complexidade das normas legais e institucionais e razão pública, mas o procedimento é outro, e eminentemente político. Há uma prioridade do justo sobre o bem, visto tratar-se de uma concepção política com alcance menor. O consenso sobreposto - diferentemente de um consenso constitucional ${ }^{15}$ - tem o papel de alcançar o equilibrio reflexivo geral e amplo na afirmação da concepção política sobre a base de suas diversas doutrinas abrangentes razoáveis, estabelecendo a justificação a partir de um consenso razoável.

Neste aspecto é importante explicitar o que entende Rawls por razoável e sua diferença com o racional. Segundo Silveira,

o razoável, aqui, diz respeito aos juizos político-morais passiveis de ser publicamente acordados pelos individuos que possuem diversas doutrinas filosóficas, morais e religiosas (doutrinas abrangentes), não operando com a categoria de verdade e expressando uma atitude reflexiva na tolerância, pois reconhece os limites da capacidade de julgar, isto é, reconhece os limites do juizo e conduz à liberdade de consciência e pensamento (SILVEIRA, 2007, p. 24).

Trata-se, portanto, de uma justificação pública (idea of public justification) deste consenso sobreposto que não é fruto da razão teórica, mas da razão prática. Assim, o razoável diz muito mais respeito àqueles juizos políticos que não podem ser tomados como uma verdade (valor teórico, racional), mas com um peso prático e pragmático. O razoável expressa uma atitude reflexiva, de tolerância, pois reconhece nossas limitações na capacidade de julgar e nos leva para a liberdade de consciência e pensamento. Essa categoria de razoável é tomada neste sentido, enquanto atitude de tolerância, numa perspectiva de uma concepção de pessoa limitada e de cidadão livre e igual.

Na obra Uma Teoria da Justiça Ralws justifica sua teoria da justiça como equidade a partir de uma perspectiva transcendental ou kantiana, através de uma concepção de pessoa moral na posição original, bem como, reconstruindo e combinando o aspecto moral com a dimensão política mediante o equilibrio reflexivo (reflective equilibrium). Já em O Liberalismo Político o autor procura distanciar-se da justificação kantiana, daí a sua crítica às doutrinas abrangentes como o Utilitarismo, e caminha na direção de uma justificação menos moral e mais política.

Em LP a "validade da concepção política não pretende abranger teorias éticas, concepções religiosas, filosóficas ou morais" (SILVEIRA, 2007, p. 28). É necessário levar em conta a primazia do justo (que é fruto do consenso justaposto, legitimado publicamente) sobre o bem (que era tomado como algo em si). A justificação é pública e o razoável sobrepõe-se sobre o racional.

A teoria política de Rawls, portanto, faz uso de uma teoria moral na estruturação dos conceitos de justo (right) e bem (good), mas não é uma concepção moral em sentido estrito. 0 razoável exige que toda a norma busque uma validade universal. Para isso ela necessita ser colocada à prova quando confrontada e posta na sua intersubjetividade. Aqui o papel do consenso sobreposto é justamente o de não operar com conceitos de verdade e correção, mas a partir do politicamente razoável que promove valores morais-políticos, através de critério da reciprocidade como: civilidade, amizade civica, cidadania, legitimidade da lei, tolerância, liberdade de opinião e oportunidades etc.

No decorrer desse trabalho procuramos acercarmo-nos dos pontos e argumentos que circundam a questão da crítica de Rawls ao Utilitarismo em O Liberalismo Político. Analiticamente pode se resumir a postura de Rawls na obra de 1993 - não obstante a rápida referência que o filósofo faz às teorias sistemáticas do Utilitarismo de Bentham, Sidgwick, Edgeworth enquanto teorias razoáveis e abrangentes - é em relação a Mill e seu conceito de individualidade que ele dedica a maior parte da crítica ao Utilitarismo.

15 Ver esta diferença entre consenso sobreposto e constitucional em: SILVEIRA, Denis Coitinho. A justificação por consenso sobreposto em John Rawls. Philósophos 12 (1): jun./jul. 2007, p. 18 e ss. 
Uma crítica caracterizada por demostrar as dificuldades de uma doutrina abrangente fundada numa perspectiva moral, não politicamente legitimada e que não confere um caráter público para as suas bases da justiça que permearão a estrutura básica (instituições) da sociedade. O Utilitarismo desconsidera a pluralidade de costumes, crenças, concepções de mundo (várias doutrinas abrangentes) das sociedades contemporâneas e não considera relevante a necessidade de principios de justiça formulados publicamente pelos cidadãos livres e iguais envolvidos, através de um neocontratualismo operado pelo véu da ignorância (veil of ingnorance) na posição original (original position).

Em sintese, a crítica ao utilitarismo gravita exatamente num aspecto especifico e restrito em $O$ Liberalismo Politico se comparado com a obra de 1971. A teoria da justiça como equidade - por meio do equilibrio reflexivo, o consenso sobreposto e a nova perspectiva de democracia constitucional - é amplamente apresentada como uma alternativa viável e adequadamente fundamentada.

\section{Referências}

BENTHAM, Jeremy. Principios da moral e da legislação. In: BENTHAM, Jeremy. Os Pensadores - Stuart Mill \& Bentham. São Paulo: Abril Cultural, 1984.

BRAGA, Antônio Frederico Saturnino. Kant, Rawls e o utilitarismo: justiça e bem na filosofia política contemporânea. Rio de Janeiro: Contraponto, 2011.

DALAQUA, Gustavo Hessmann. John Stuart Mill vs. John Rawls: a comparison. Seara Filosófica, Curitiba, n. 8, Inverno, 2014, p. 61-69. Disponivel em: https://periodicos.ufpel.edu.br/ojs2/index.php/searafilosofica/ article/view/3637.

DALSOTTO, Lucas Mateus. A Primazia do Justo sobre o Bem: as criticas de Rawls ao Utilitarismo. Disponivel em: https://repositorio.ucs.br/xmlui/handle/11338/785. Acesso em: 16 nov. 2018

DALSOTTO, Lucas Mateus. Justificação Moral e Acordo Político: sobre a possibilidade de uma complementariedade entre um construtivismo moral e um construtivismo política na teoria de Rawls. Barbarói, Santa Cruz do Sul, Edição Especial, n. 42, p. 75-87, jul./dez. 2014.

DALSOTTO, Lucas Mateus. A Primazia do Justo sobre o Bem na Filosofia Política de John Rawls. Intuitio, Porto Alegre. v. 7, n. 1. jun. 2014, p. 125-138. Disponivel em: https://revistaseletronicas.pucrs.br/ojs/index.php/intuitio/article/view/17209. https://doi.org/10.15448/19834012.2014.1.17209
DALSOTTO, Lucas Mateus. O Construtivismo na Filosofia de John Rawls. Revista Estudos Filosóficos, São João del Rei, n. 12, p. 104-116, dez. 2014. Disponivel: http:// www.ufsj.edu.br/revistaestudosfilosoficos.

DALSOTTO, Lucas Mateus. Os limites da teoria de John Rawls: uma teoria política e não metafísica. In: ROANI, CARVALHO, M.; NASCIMENTO, M. M.; WEBER, T. Justiça e direito. 2015. (Coleção XVI Encontro ANPOF)

DE PAUL, Michael R. Reflective Equilibrium. Encyclopedia of Philosophy. 2 ed. Macmillan: Boston, 2005. p. $290-295$

ESTEVES, Júlio. As criticas ao utilitarismo por Rawls. Ethic@, Florianópolis. v. 1, n. 1, jun. 2002, p. 81-96. Disponivel em: https://periodicos.ufsc.br/index.php/ethic/ article/view/14536.

FABIAN, Eloi Pedro. Elementos centrais da obra Liberalismo Político de John Rawls - Primeira e segunda conferências. Clareira: revista de Filosofia da Região Amazônica, Porto Velho, v. 1, n. 2, ago./ dez. 2014, p. 139-159. Disponivel em: https://www.periodicos.unir. br/index.php/clareira/article/view/3584/2464.

FABIAN, Eloi Pedro. Utilitarismo e liberalismo politico em John Stuart Mill. Revista Filosofazer. Passo Fundo, v. 48, jan./jun. 2016, p. 79-106. Disponivel em: http://filosofazer.ifibe.edu.br/index.php/filosofazer/ article/viewFile/189/200. https://doi.org/10.3917/ empa.106.0079

FORST, Rainer. Contextos de Justiça: filosofia política para além de liberalismo e comunitarismo. São Paulo: Boitempo, 2010.

GONDIM, Elnora \& RODRIGUES, Osvaldino Marra. John Rawls: educação, cidadania e equilibrio reflexivo. Revista Filosofia Capital, Brasilia, v. 6, n. 12, jan/2011, p. 25-33. Disponivel em: http://www. filosofiacapital.org/ ojs-2.1.1/index.php/filosofiacapital/article/view/158.

KIMLICKA, Will. Filosofia Politica Contemporânea: uma introdução. São Paulo: Martins Fontes, 2006.

MAFFETTONE, Sebastiano; DWORKIN, Donald. Il fundamento del Liberalismo. Roma: Laterza, 1996.

MAFFETTONE, Sebastiano; DWORKIN, Donald. Rawls: una introduzione. Roma: Laterza, 2010.

MAFFETTONE, Sebastiano; DWORKIN, Donald. Utilitarismo e Teoria della Giustizia. Napoli: Bibliopolis, edizioni di filosofia e scienze, 1992.

MAFFETTONE, Sebastiano; DWORKIN, Donald. Introduzione a Rawls. Roma: Laterza, 2010.

MAFFETTONE, Sebastiano; DWORKIN, Donald. Rawls: a introduction. London: Poly Press, 2007.

MANDLE, Jon; REIDY, David, A. Utilitarianism. In: MANDLE, Jon; REIDY, David, A. The Cambridge Rawls Lexicon. Cambridge University Press, 2015, p. 858-865. https:// doi.org/10.1017/CBO9781139026741.222

MILL, John Stuart. A Liberdade / Utilitarismo. São Paulo: Martins Fontes, 2000. 
MILL, John Stuart. Da definição de economia política e do método de investigação próprio a ela. In: MILL, John Stuart. Os Pensadores: Stuart Mill \& Bentham. São Paulo: Abril Cultural, 1984

MILL, John Stuart. Considerações sobre o governo representativo. São Paulo: IBRASA, 1964.

MULGAN, Tim. Utilitarismo. Petrópolis: Editora Vozes, 2012

NUSSBAUM, Martha. Fronteiras da Justiça: deficiência, nacionalidade, pertencimento à espécie. Tradução de Susana de Castro. São Paulo: Editora WMF Martins Fontes, 2013

OLIVEIRA, Nythamar Fernandes de. Rawls. Rio de Janeiro: Jorge Zahar, 2003

OLIVEIRA, Nythamar Fernandes de. Tratactus ethico-politicus: genealogia do ethos moderno. Porto Alegre: EDIPUCRS, 1999.

RAWLS, John. Uma Teoria da Justiça. São Paulo: Martins Fontes, 2000.

RAWLS, John. Liberalismo Politico. São Paulo: Ática, 2000.

RAWLS, John. O Direito dos Povos. São Paulo: Martins Fontes, 2004

RAWLS, John. Conferências sobre a História da Filosofia Politica. São Paulo: Editora WMF Martins Fontes, 2012.

RAWLS, John. Two concepts of rules. In: RAWLS, John, The Philosophical Review. Vol. 64, n. 1, jan. 1955, p. 3-32. Disponivel em: https://www.jstor.org/stable/i338194.

\section{https://doi.org/10.2307/2182230}

REYNOLDS, Alan. Reconsidering the Connection between John Stuart Mill and John Rawls. Minerva - An Internet Journal of Philosophy, 2013, p. 1-30. Disponivel em: https://philpapers.org/rec/REYRTC-3.

RILEY, Jonathan. Rawls, Mill and Utilitarianism. In: MANDLE, John; REIDY, David A. A companion to Rawls. Library of Congress Cataloging, 2014. p. 397-412.

SCHEFFLER, Samuel. Rawls and Utilitarianism. In: FREEMAN, Samuel. The Cambridge companion to Rawls. Edited by Samuel Freeman. Cambridge: Cambridge University Press, 2003, p. 426- 459

SCHEFFLER, Samuel. Consequentialism and its critics. Oxford: Oxford University Press, 2009.

SIDGWIG, Henry. The methods of ethics. Indianapolis: Hackett Publishing Company, 2010.

SILVEIRA, Denis Coitinho. Epistemologia Moral Coerentista em Rawls. Dissertatio. Pelotas. v. 34, p. 161-182, 2011. Disponivel em: https://periodicos.ufpel.edu.br/ ojs2/index.php/dissertatio/article/view/8700. https:// doi.org/10.15210/dissertatio.v34io.8700
SILVEIRA, Denis Coitinho. Posição Original e Equilíbrio Reflexivo em John Rawls: o problema da Justificação. Trans/Form/Ação, São Paulo, v. 32, n. 1, p. 139-157, 2009. Disponivel em: https://www.scielo.br/ scielo. php?pid $=$ S0101 $=31732009000100009-\&$ scriptsci_abstract\&tlng=pt. https://doi.org/10.1590/S010131732009000100009

SILVEIRA, Denis Coitinho. A Justificação por Consenso Sobreposto em John Rawls. Philosophos, v. 12, n. 1, p 11-37, jan./jun. 2007. Disponivel em: https://www.revistas.ufg.br/index.php/philosophos/article/view/4764.

SILVEIRA, Denis Coitinho. Ensaios sobre Ética: complementariedade entre uma ética dos princípios e das virtudes. Pelotas: Editora e Gráfica Universitária, 2008. (Coleção Dissertatio Filosofia).

SILVEIRA, Denis Coitinho. The utilitarian alternative. In: VOICE, Paul. Rawls explained: from fairness to utopia. Open Court: Chicago, 2011, p. 49-54. https://doi. org/10.5216/phi.v12i1.4764

WILLIAM, Bernard. Moral: uma introdução à ética. São Paulo: Martin Claret, 2005.

\section{Eloi Fabian}

Doutor em Filosofia pela Pontifícia Universidade Católica do Rio Grande do Sul (2008); professor Adjunto IV da UFFS - Universidade Federal da Fronteira Sul Campus de Erechim

\section{Endereço para correspondência}

Eloi Fabian

Universidade Federal da Fronteira Sul, Campus de Erechim.

Av. Dom João Hoffman, $n^{\circ}$ 313, Fátima

Erechim, RS - Brasil

99700000 